\title{
Role of microglial amylin receptors in mediating beta amyloid $(A \beta)$-induced inflammation
}

Wen Fu ${ }^{1}$, Vlatka Vukojevic ${ }^{1}$, Aarti Patel ${ }^{1}$, Rania Soudy ${ }^{1,2}$, David MacTavish' ${ }^{1}$, David Westaway ${ }^{1,3,4}$, Kamaljit Kaur ${ }^{5}$, Valeri Goncharuk ${ }^{6}$ and Jack Jhamandas ${ }^{1 *}$

\begin{abstract}
Background: Neuroinflammation in the brain consequent to activation of microglia is viewed as an important component of Alzheimer's disease (AD) pathology. Amyloid beta (Aß) protein is known to activate microglia and unleash an inflammatory cascade that eventually results in neuronal dysfunction and death. In this study, we sought to identify the presence of amylin receptors on human fetal and murine microglia and determine whether $A \beta$ activation of the inflammasome complex and subsequent release of cytokines is mediated through these receptors.

Methods: The presence of dimeric components of the amylin receptor (calcitonin receptor and receptor activity modifying protein 3) were first immunohistochemically identified on microglia. Purified human fetal microglial (HFM) cultures were incubated with an in vivo microglial marker, DyLight 594-conjugated tomato lectin, and loaded with the membrane-permeant green fluorescent dye, Fluo-8L-AM for measurements of intracellular calcium $\left[\mathrm{Ca}^{2+}\right]$ i. HFM and BV-2 cells were primed with lipopolysaccharide and then exposed to either human amylin or soluble oligomeric $A \beta_{1-42}$ prior to treatment with and without the amylin receptor antagonist, $A C 253$. Changes in the inflammasome complex, NLRP3 and caspase-1, were examined in treated cell cultures with Western blot and fluorometric assays. RT-PCR measurements were performed to assess cytokine release. Finally, in vivo studies were performed in transgenic mouse model of AD (5xFAD) to examine the effects of systemic administration of AC253 on markers of neuroinflammation in the brain.
\end{abstract}

Results: Acute applications of human amylin or $A \beta_{1-42}$ resulted in an increase in $\left[\mathrm{Ca}^{2+}\right]$ i that could be blocked by the amylin receptor antagonist, AC253. Activation of the NLRP3 and caspase-1 and subsequent release of cytokines, TNFa and IL-1 $\beta$, was diminished by AC253 pretreatment of HFMs and BV2 cells. In vivo, intraperitoneal administration of AC253 resulted in a reduction in microglial markers (Iba-1 and CD68), caspase-1, TNFa, and IL-1 3 . These reductions in inflammatory markers were accompanied by reduction in amyloid plaque and size in the brains of 5xFAD mice compared to controls.

Conclusion: Microglial amylin receptors mediate Aß-evoked inflammation, and amylin receptor antagonists therefore offer an attractive therapeutic target for intervention in AD.

Keywords: Microglia, Amylin receptor, $\beta$-amyloid, AC253 peptide, Inflammasome, NLRP3, Caspase-1, Cytokines, Alzheimer's disease

\footnotetext{
* Correspondence: jack.jhamandas@ualberta.ca

${ }^{1}$ Department of Medicine (Neurology), Neuroscience and Mental Health

Institute, University of Alberta, 530 Heritage Medical Research Centre,

Edmonton, AB T6G 2S2, Canada

Full list of author information is available at the end of the article
}

(c) The Author(s). 2017 Open Access This article is distributed under the terms of the Creative Commons Attribution 4.0 International License (http://creativecommons.org/licenses/by/4.0/), which permits unrestricted use, distribution, and reproduction in any medium, provided you give appropriate credit to the original author(s) and the source, provide a link to the Creative Commons license, and indicate if changes were made. The Creative Commons Public Domain Dedication waiver (http://creativecommons.org/publicdomain/zero/1.0/) applies to the data made available in this article, unless otherwise stated. 


\section{Background}

Alzheimer's disease (AD), the most common form of dementia, is characterized by synaptic loss, deposition of misfolded proteins (amyloid beta protein, $A \beta$, and hyperphosphorylated tau), and neuroinflammation [1]. Microglia, the main immune cells in the brain, appear central to the initiation and progression of neuroinflammation in $\mathrm{AD}$ [2-4]. These cells are activated and recruited to amyloid plaques, phagocytose $A \beta$, and secrete cytokines [5]. Initiation of such an inflammatory cascade results from $A \beta$ recruitment of intracellular cytosolic multiprotein complexes termed "inflammasomes" and the subsequent activation of microglial caspase-1 [6-8]. The inflammasome NLRP3, a member of the PYHIN family of proteins, and ASC, an adaptor protein, are deemed to be important in the context of neurodegenerative processes [9]. Caspase-1 generates inflammatory responses through cleavage and release of the injurious cytokines, IL-1 $\beta$ and IL-18, on to adjacent neurons $[6,10]$. The release of such inflammatory cytokines also elicits upregulation of $A \beta$ via increased APP processing [11], thus perpetuating a vicious cycle of $A \beta$-induced neuronal damage. Therefore, mechanisms whereby $A \beta$ activates microglia to initiate this inflammatory cascade are crucial to understanding the interplay between microglia and neuronal viability in $\mathrm{AD} . \mathrm{A} \beta$ is postulated to be endocytosed into murine microglia [7] or alternately interact with a variety of putative target receptors on the microglial membrane $[12,13]$. In the course of examining the presence of amylin receptors on neurons, we made the surprising observation that amylin receptors are also present on microglia $[14,15]$. We thus hypothesized that microglial amylin receptors may serve as a portal of expression of $A \beta$-induced inflammatory responses.

Amylin receptors (AMYs) consist of dimerized calcitonin receptor (CTR) with receptor activity-modifying proteins (RAMPs) and belong to class B GPCR. Amylin, the endogenous peptide that binds to the amylin receptor, mediates glycemic regulation, control of energy balance, and cognitive processes and modulates innate immunity through regulatory $\mathrm{T}$ cells $[16-18]$. We have previously shown that the deleterious effects of $A \beta$ on cultured human and rat neurons are expressed through the amylin receptor and that amylin receptor antagonists, such as AC253, are neuroprotective against A $\beta$ toxicity $[14,19]$. Moreover, application of amylin receptor antagonists reverses impairment of $\mathrm{A} \beta$ or human amylin (hAmylin)-induced depression of hippocampal long-term potentiation, a cellular surrogate of memory [20]. Herein, we show that amylin receptors are not only present on human fetal and murine microglia but are functional in mediating $\mathrm{A} \beta$-induced activation of an intracellular inflammatory cascade that results in the release of cytokines. Chronic systemic administration of cyclized form of the amylin receptor antagonist, AC253 (cAC253), which is readily brain penetrant, reduced markers of microglial activation and cytokine release in a mouse model of AD [15]. We also observed a parallel decrease in amyloid plaque formation in cAC253-treated $\mathrm{AD}$ mice.

\section{Methods}

All experiments were conducted in compliance with the guidelines set by the Canadian Council for Animal Care and with the approval of the Human Research Ethics Board and Animal Care Use Committee (Biomedical Sciences) at the University of Alberta.

\section{Cell cultures}

Two different types of microglial, primary cultures of human fetal microglia and mouse microglial BV2 cell line, were used for in vitro testing of amylin receptor function. This approach provided confirmation of the presence of microglial amylin receptors across species and cross-validated our observations on the function of amylin receptors in both primary cell cultures and a frequently used cell line. Primary mixed glial cultures were prepared from 12- to 15-gestational-week fetuses as previously reported [21, 22]. Briefly, the meninges and blood vessels were removed and the brain tissue was washed in minimum essential medium and mechanically dissociated by repeated trituration through a 20-gauge needle. Cells were centrifuged at $1500 \mathrm{~g}$ for $10 \mathrm{~min}$ and re-suspended in minimum essential medium with $10 \%$ fetal bovine serum. The cultures were grown in a $5 \%$ $\mathrm{CO}_{2}$ humidified incubator at $37{ }^{\circ} \mathrm{C}$. After mixed glial cultures were completely confluent, human fetal microglia (HFM) were isolated by shaking flasks at $100 \mathrm{rpm}$ (IKA KS-260, IKA Works, Wilmington, NC) for $1 \mathrm{~h}$ at $37{ }^{\circ} \mathrm{C}$. The media was then collected and centrifuged at $2500 \mathrm{RCF}$ for $5 \mathrm{~min}$ at $4{ }^{\circ} \mathrm{C}$. Cell pellets were resuspended in microglia plating media (MEM $+10 \%$ FBS $+1 \%$ penicillin/streptomycin). HFM were plated at a $2 \times 10^{5}$ cells per milliliter density, and microglia were allowed to attach overnight before further use for experiments. BV2 cells (kindly provided by Dr. T. Trang, University of Calgary) were cultured in DMEM/F12 media with $10 \%$ FBS. For all in vitro experiments, primary human fetal microglial cultures and BV2 cell cultures, each experiment was performed on a fresh batch of cell cultures and repeated a minimum of four times. Statistical analysis was performed on mean data.

In order to characterize the antagonist activity of cAC253 at subtypes of amylin receptors, we compared hAmylin-generated cAMP responses in stably expressed AMY1, AMY2, and AMY3 and CTR receptors in 
HEK293 cells and wild-type HEK (HEK-WT) cells (Additional file 1).

\section{Western blot}

Frozen brain tissues or cultured cells were homogenized in cold RIPA buffer with protease inhibitors and proteins were quantified with BCA assay (BioRad, Mississauga, ON, Canada). Proteins were loaded at $50 \mu \mathrm{g}$ per lane on a $12 \%$ polyacrylamide gel. Proteins were transferred to nitrocellulose membrane and then blocked with LiCor blocking buffer. Blots were further incubated with primary antibodies overnight at $4{ }^{\circ} \mathrm{C}$ on a shaker. Primary antibody used for Iba1 (1:500, rabbit, Wako), CD68 (1:500, mouse monoclonal, Dako), caspase-1 (1:1000, rabbit, Abcam), NLRP3 (1:1000, rabbit, Millipore), and $\beta$-actin (1:10,000 mouse, Sigma-Aldrich). IRDye $800 \mathrm{CW}$ goat anti-rabbit and IRDye $680 \mathrm{CW}$ goat anti-mouse (LiCor, 1:10,000) were used as secondary antibodies. Blots were imaged using LiCor Odyssey image system.

\section{ELISA (enzyme-linked immunosorbent assay)}

Mouse brain cytokines, TNF $\alpha$ (Invitrogen), IL-6 (interleukin-6, Abcam), and IL-1 $\beta$ (Thermoscientific) were quantified using colorimetric ELISA kits following the protocol provided. In brief, hemi-brains were homogenized on ice for $3 \mathrm{~h}$ in RIPA buffer with protease inhibitor. The homogenized brain was centrifuged at $21,000 \mathrm{~g}$ for $20 \mathrm{~min}$ at $4{ }^{\circ} \mathrm{C}$. The supernatant was collected and diluted with PBS buffer $\mathrm{pH} 7.4$ (1:100) prior its plate loading. Standard curves were plotted using the cytokine standards provided in the ELISA kits. All samples were analyzed in duplicate. The plate is measured at $450 \mathrm{~nm}$ and data expressed as $\mathrm{pg} / \mathrm{mg}$ wet tissue.

\section{Cytokines PCR assay}

The PCR array for TNF $\alpha$, IL1 $\beta$, and IL23 gene expression used the $\mathrm{RT}^{2}$ Profiler PCR Array system (96-well assay plate, SABiosciences) following product instruction. Briefly, HFM were plated in a six-well plate for $24 \mathrm{~h}$, pre-treated with/without AC253 $10 \mu \mathrm{M}$ for $24 \mathrm{~h}$, and then exposed to either hAmylin $(1 \mu \mathrm{M})$ or $A \beta_{1-42}$ $(1 \mu \mathrm{M})$ for $6 \mathrm{~h}$. RNA was isolated with Rneasy Mini kit (Qiagen) as per the product instructions. For each PCR Array, $4 \mu \mathrm{g}$ of total RNA were used to prepare cDNA with the appropriate first strand kit from SABiosciences. The cDNA was characterized on the iCycler ${ }^{\circ}$ iQ RealTime PCR System (Bio-Rad Laboratories) using the RT2 Profiler PCR Arrays. The resulting raw data were then analyzed using the PCR Array Data Analysis Template and expressed as gene expression fold-change after treatment compared to the control untreated HFM cultures.

\section{Immunofluorescent-histological staining}

For cultured cell immunofluorescent staining, cells were plated on Lab-TEK chamber slide (ThermoFisher) and fixed with $4 \%$ paraformaldehyde (PAF) in PBS, then permeabilized with $0.3 \%$ Triton X-100 in PBS and blocked with $2 \%$ BSA $+10 \%$ goat serum for $1 \mathrm{~h}$. Primary antibodies used Iba-1 (1:100, Dako), CTR (1:50, ThermoFisher, Catalog \# PA1-84457, Lot \# QJ2098825 and RI2275863), RAMP3 (1:100, Abcam), A $\beta$ (6E10, 1:300, Covance), and NLRP3 (1:300, Millipore) followed fluorescent secondary antibody (goat anti-mouse Alexa Fluor-546 and goat anti-rabbit Alexa Fluor-488) and were nuclear-stained with DAPI $(0.1 \mu \mathrm{g} / \mathrm{ml}$, ThermoFisher). Fluorescent dyes, DyLight-594 Lectin (Vector), HiLyte 555-labled $\mathrm{A} \beta_{1-42}$ (AnaSpec), and caspase-1 (FAM-FLICA caspase 1 kit, ImmunoChemistry Technologies) were used following product instruction. Fluorescent microscopy images were acquired with an Axioplan-2 fluorescence microscope with AxioVision software (Carl Zeiss Ltd., Toronto, ON, Canada).

For human brain immunohistochemical staining, 20$\mu \mathrm{m}$-thick brain sections were cut from 1-cm-thick coronal block of the human inferior temporal gyrus (IFG) of an AD brain (Braak Stage 6) obtained from the Netherlands Brain Bank. Prior to immunohistochemistry, the sections were pretreated with absolute methanol and $3 \%$ hydrogen peroxide for $10 \mathrm{~min}$ to avoid visualizing endogeneous peroxidase activity, followed by three $10 \mathrm{~min}(3 \times 10 \mathrm{~min})$ washes in TBS (Tris-buffered saline). Then, they were incubated overnight at $4{ }^{\circ} \mathrm{C}$ with the rabbit polyclonal anti-CTR antibody (ThermoFisher Scientific) at a working dilution 1:20 in Supermix (TBS containing $0.3 \%$ Triton $\mathrm{X}-100$ and $2.5 \mathrm{mg} / \mathrm{ml}$ gelatin). The next day, the sections were washed in TBS $(3 \times 10$ $\mathrm{min})$ and then incubated in biotinylated goat anti-rabbit IgG, diluted 1:400 in Supermix for $2 \mathrm{~h}$ at room temperature. Following incubation, the sections were washed in TBS $(3 \times 10 \mathrm{~min})$ and processed by the avidin-biotin complex (ABC) (Vector Laboratories, Burlingame, $\mathrm{CA}$ ) for $2 \mathrm{~h}$ at room temperature. After washing in TBS $(3 \times 10 \mathrm{~min})$, reaction products of dark blue color were visualized with $3,3^{\prime}$-diaminobenzidine- $4 \mathrm{HCl}$ (20 mg/100 ml, Sigma) in TBS containing 0.2\% ammonium nickel sulphate and $3 \% \mathrm{H}_{2} \mathrm{O}_{2}$. Several sections were immunostained for CTR as mentioned above and after final washing in TBS were incubated overnight at $4{ }^{\circ} \mathrm{C}$ with either Iba- 1 antibody (1:100, Dako) or RAMP3 rabbit polyclonal antibody (Abcam, Catalog \# ab78017, Lot \# 816327; Catalog \# ab197372, Lot \# GR2042843) at working dilution of 1:500 in Supermix. The next day, the sections were washed in TBS $(3 \times 10 \mathrm{~min})$ and then incubated in biotinylated goat anti-rabbit IgG diluted 1:400 in Supermix for $2 \mathrm{~h}$ at room temperature. Further, the sections were washed $3 \times 10 \mathrm{~min}$ in TBS and 
processed with $A B C$ for $2 \mathrm{~h}$ at room temperature. After washing $3 \times 10 \mathrm{~min}$ in TBS, the sections were treated with 3,3'-diaminobenzidine- $4 \mathrm{HCl} \quad(20 \mathrm{mg} / 100 \mathrm{ml}$, Sigma) in TBS containing $3 \% \mathrm{H}_{2} \mathrm{O}_{2}$, resulting in the reaction product of yellow color. Thus, after CTR + Iba-1 dual immunostaining of the IFG sections, the neuronal final reaction product of dark blue color was associated with the presence of the CTR whereas deposit of yellow color was coupled with Iba-1 or RAMP3. Brightfield images were acquired on Axioplan 2 microscope (Zeiss) with AxioVision software (ver 4.8.2, Zeiss). The ability of the CTR and RAMP3 antibodies to detect these proteins was verified using AMY3-HEK293 transfected cells and wild-type HEK293 cells (Additional file 1 and Additional file 2: Figure S1A). We also performed siRNA RAMP3 transfections of BV2 microglial cells and compared detection of the RAMP3 protein in these cells compared to non-transfected cells (Additional file 1 and Additional file 2: Figure S1B).

For in-cell Western blot cyclic adenosine monophosphate (cAMP) quantification, mouse monoclonal anticAMP (R\&D Systems) was used as a primary antibody and IRDye 700 goat anti mouse antibody (LI-COR) was used as a secondary antibody. Plates were imaged using an Odyssey Infrared Imaging System (LI-COR), and the integrated intensity was normalized to the total cell number on the same well as previously described [23].

\section{$\mathrm{Ca}^{2+}$ imaging}

$\mathrm{Ca}^{2+}$ concentration were monitored with confocal microscopy as described previously [23, 24]. Briefly, HFMs were plated on glass coverslips pre-coated with poly-Lornithine and incubated at $37{ }^{\circ} \mathrm{C}$ for $12-36 \mathrm{~h}$. Then, incubated with $5 \mu \mathrm{M}$ of membrane-permeant fluorescent $\mathrm{Ca}^{2+}$-sensitive dye Fluo-8L-AM (AAT Bioquest, Inc., Sunnyvale, CA) for $40 \mathrm{~min}$ at room temperature (20$23{ }^{\circ} \mathrm{C}$ ) within $<2 \mathrm{~h}$ before imaging. For $\mathrm{Ca}^{2+}$ imaging, the superfusate of ion content similar to extracellular brain fluid thus contain the following: $130 \mathrm{mM} \mathrm{NaCl}$, $4 \mathrm{mM} \mathrm{KCl}, 1 \mathrm{mM} \mathrm{MgCl} 2,2 \mathrm{mM} \mathrm{CaCl} 2,10 \mathrm{mM}$ HEPES, and $10 \mathrm{mM}$ glucose $(\mathrm{pH} 7.35)$ was applied at a rate of $3 \mathrm{ml} / \mathrm{min}$ using a roller pump (Watson-Marlow Alitea, Sin-Can, Calgary, $A B$, Canada). $A \beta_{1-42}$ and hAmylin were dissolved in sterile bidistilled water at $1 \mathrm{mM}$ stock solution and incubated at room temperature for $10 \mathrm{~min}$ before dilution with superfusate for the final used concentrations. Fluorescence intensity was monitored with a FV-300 laser-scanning confocal microscope (Olympus FV300, Markham, Ontario, Canada) equipped with an argon laser $(488 \mathrm{~nm})$ and excitation/emission filters (FF02-520/28-25; Semrock, Inc.) for an emission wavelength at $514 \mathrm{~nm}$, measured with a numerical aperture of 0.95 20x XLUMPlanF1 objective (Olympus). Images were acquired at scan rates of $1.25-1.43$ per second using a $2-3 \times$ digital zoom at full-frame $(512 \times 512$ pixel $)$ resolution. Regions of interest were drawn around distinct cell bodies, and analysis of time courses of change in fluorescence intensity were generated with FluoView software (version 4.3; Olympus).

\section{Peptides and reagents}

AC253 peptide was cyclized to improve its stability and brain penetration when administered systemically [15]. To cyclize the AC253 peptide (cAC253) via the flanking D-cysteines, the crude peptide $(61.2 \mathrm{mg})$ was dissolved in $0.1 \mathrm{mM}$ Tris buffer pH 8.3 having $20 \%$ of DMSO to accelerate disulfide bond formation, and the mixture was stirred at room temperature in an open flask for $48 \mathrm{~h}$ and further purified on RP-HPLC (reversed phase highperformance liquid chromatography).

Soluble oligomeric $A \beta_{1-42}$ or the inverse sequence peptide $A \beta_{42-1}$, hAmylin, and AC253 were prepared according to published protocols $[14,25]$. Human amylin and AC253 were purchased from American Peptide (Sunnyvale, CA) and $\mathrm{A} \beta$ peptides from rPeptide (Bogart, GA). The human amylin was prepared in $1 \mathrm{mM}$ stock solution in water and further diluted to the final application concentration with cell culture media as previously described [14].

\section{In vivo experiments and mouse brain tissue processing}

For in vivo experiments, intraperitoneal injection (ip) administration of cAC253 was carried out in transgenic 5XFAD mice [15], and wild-type littermate control mice (both male and female) were obtained from Dr. David Westaway (University of Alberta). These mice were equally and randomly distributed into four groups, TgNS $(n=10), \operatorname{Tg}$-cAC253 $(n=10)$, Wt-NS $(n=10)$, and Wt-cAC253 $(n=10)$. Mice received ip either normal saline (NS) or cAC253 $(200 \mu \mathrm{g} / \mathrm{kg})$ three times a week starting at 6.5 months of age for 5 weeks. Mice were housed under standard laboratory conditions (12/12-h light/dark cycle, lights on at $0600 \mathrm{~h}$ ) with a room temperature of $21{ }^{\circ} \mathrm{C}$. Water and food were available ad libitum. After completion of treatments, all mice were sacrificed with an overdose of isoflourane anesthetic and perfused transcardially with saline, and the brains were harvested. The right hemisphere was frozen for biochemical analysis (Western blot, ELISA), and the left hemisphere was fixed with PAF for $4 \mathrm{~h}$ at $4{ }^{\circ} \mathrm{C}$. These brain tissues were further processed with modified CLARITY protocol (http://www.chunglabresources.com/ cl1\#cl-protocol). Briefly, the fixed brain tissue was transferred to hydrogel monomer solution ( $4 \%$ acrylamide, $4 \%$ PFA, and 1xPBS (phosphate-buffered saline)) at $4{ }^{\circ} \mathrm{C}$ for $24 \mathrm{~h}$ and, subsequently, to a 24-well plate, merged in fresh hydrogel solution, and the tissue was brought to $37{ }^{\circ} \mathrm{C}$ till formation of the gel. Thick sagittal slices 
$(400 \mu \mathrm{m})$ were cut on an HR2 Slicer (Sigman Electronic, Germany). The thicker brain sections were cleared with $8 \%$ SDS in PBS for $24 \mathrm{~h}$, followed by $0.3 \%$ Triton X-100 in PBS for $24 \mathrm{~h}$, blocking the section in $2 \% \mathrm{BSA}-10 \%$ goat serum for $4 \mathrm{~h}$. A modified thioflavin $\mathrm{S}$ staining was used for detecting $A \beta$ plaques. Briefly, the brain sections were rinsed with distilled water, dropped with thioflavin $\mathrm{S}$ $(0.0125 \%$ in $50 \%$ ethanol) for $5 \mathrm{~min}$, further washing with $50 \%$ ethanol and water. Then, these sections were incubated with CD68 antibody (1:50, DAKO) at $4{ }^{\circ} \mathrm{C}$ for overnight. After washing with $\mathrm{PBS}$, these sections were incubated with goat-anti mouse Alexa-fluor546 (1:200, Invitrogen) at RT for $4 \mathrm{~h}$. Sections were cleared with $8 \%$ SDS for $24 \mathrm{~h}$ followed by a 24-h wash with PBS-Triton$\mathrm{X} 100$ solution. Images were visualized using fluorescence microscopy (Axioplan-2, Carl Zeiss Ltd). Amyloid plaque size and area were analyzed with Image J software.

\section{Statistical analysis}

The statistical data are presented as mean \pm SEM unless otherwise specified. Significance was determined by oneway analysis of variance (ANOVA), followed by Tukey's post hoc test with Prism software (GraphPad Prism 5, GraphPad Software, San Diego, CA). Differences between groups were considered to be significant at $p<0.05$.

\section{Results}

Microglial cells expressed functional AMY receptors

In primary HFM cultures, the microglia population comprises more than $90 \%$ of cells as judged by staining with microglial markers, Iba-1, and DyLight 594 lectin (Fig. 1a). To establish AMY expression in these microglial cells, we first immunohistochemically identified the presence of CTR and RAMP3 (Fig. 1b). We next assessed functionality of AMYs using live-cell calcium imaging (with Fluo-8) and confocal microscopy of identified microglia (Fig. 1c). Bath applications of either monomeric human amylin (hAmylin) or soluble oligomeric $A \beta_{1-42}(1 \mu \mathrm{M})$ to HFM for 30 s produced a robust $\mathrm{Ca}^{2+}$ increase within $1 \mathrm{~min}$ after entry of the peptide within the imaging chamber. These $\mathrm{Ca}^{2+}$ increases displayed a sharp peak and returned to base line within 2 min (Fig. 1e, f), and they are similar to responses evoked by these peptides in HEK293 cells expressing the AMY3 receptor subtype [23]. The transient elevations in $\mathrm{Ca}^{2+}$ due to hAmylin or $\mathrm{A} \beta_{1-42}$ applications were abolished by prior application of the amylin receptor antagonist, AC253 (Fig. 1h, i), suggesting that these responses

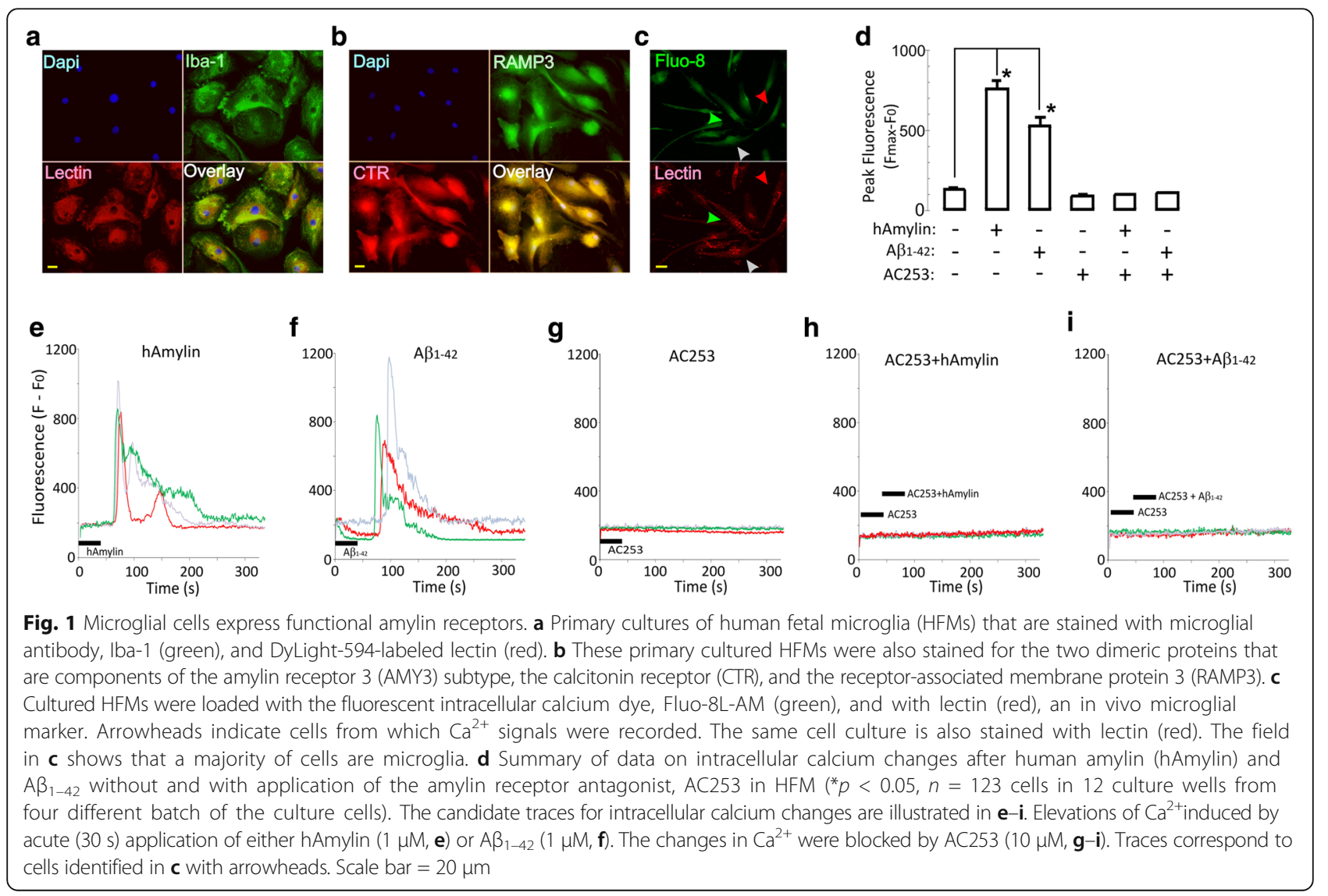


are AMY receptor-mediated. AC253 applied alone did not evoke any alterations in intracellular $\mathrm{Ca}^{2+}$ levels (Fig. 1g). Pooled data shown in Fig. 1d are from 123 HFM in 12 culture wells from four different batches of HFM cultures. Finally, we also confirmed, using inferior temporal gyrus sections from autopsied AD patient brain, that adult human microglia were immunopositive for CTR and RAMP3 (Fig. 2a-e). In addition, BV2 cells, a mouse microglia cell line, also expressed amylin receptors (Fig. 2f, g). In these cells, exposure to $A \beta_{1-42}$, $(1 \mu \mathrm{M})$ resulted in an uptake of the peptide into the microglia and formation of plaque-like structures on the cell surface as determined by thioflavin $\mathrm{S}$ staining (Fig. 2g).

\section{$A \beta$ induces $A M Y$ receptor-mediated microglial immune responses}

We next sought to examine the potential role of microglial AMY receptors in $A \beta$-induced activation of the intracellular inflammasome cascade. We observed levels of NLRP3, the best studied of inflammasomes in the context of $\mathrm{AD}$, to be low under basal conditions but increased significantly after hAmylin or $A \beta$ stimulation
(Fig. 3a). This stimulated increase in the NLRP3 expression was attenuated in the presence of the AMY antagonist, AC253, thus identifying a role for AMY receptors in activation of the inflammasome cascade (Fig. 3b). Western blot analysis further confirmed AMY receptormediated changes in NLRP3 expression (Fig. 3c, d).

Since inflammasomes function as intracellular sensors for danger signals and in response trigger activation of caspase- 1 and subsequent cleavage and release of cytokines, we also examined the role of AMY receptors in these downstream events. Both $A \beta$ and hAmylin increased caspase-1 expression in HFM and BV2 cell cultures, a response that was blunted by AC253 (Fig. 4a, b). Additionally, using RT-PCR assay, we also identified $\mathrm{A} \beta$ and hAmylin-mediated increases in IL1 $\beta$, and TNF $\alpha$, but not IL23, that were significantly attenuated by AC253 (Fig. 4c).

In vivo therapeutic targeting to block AMYs reduces brain inflammation and amyloid plaque formation in transgenic animal model of $A D$

We have recently synthesized a cyclized form of AC253 (cAC253), which retains the neuroprotective properties

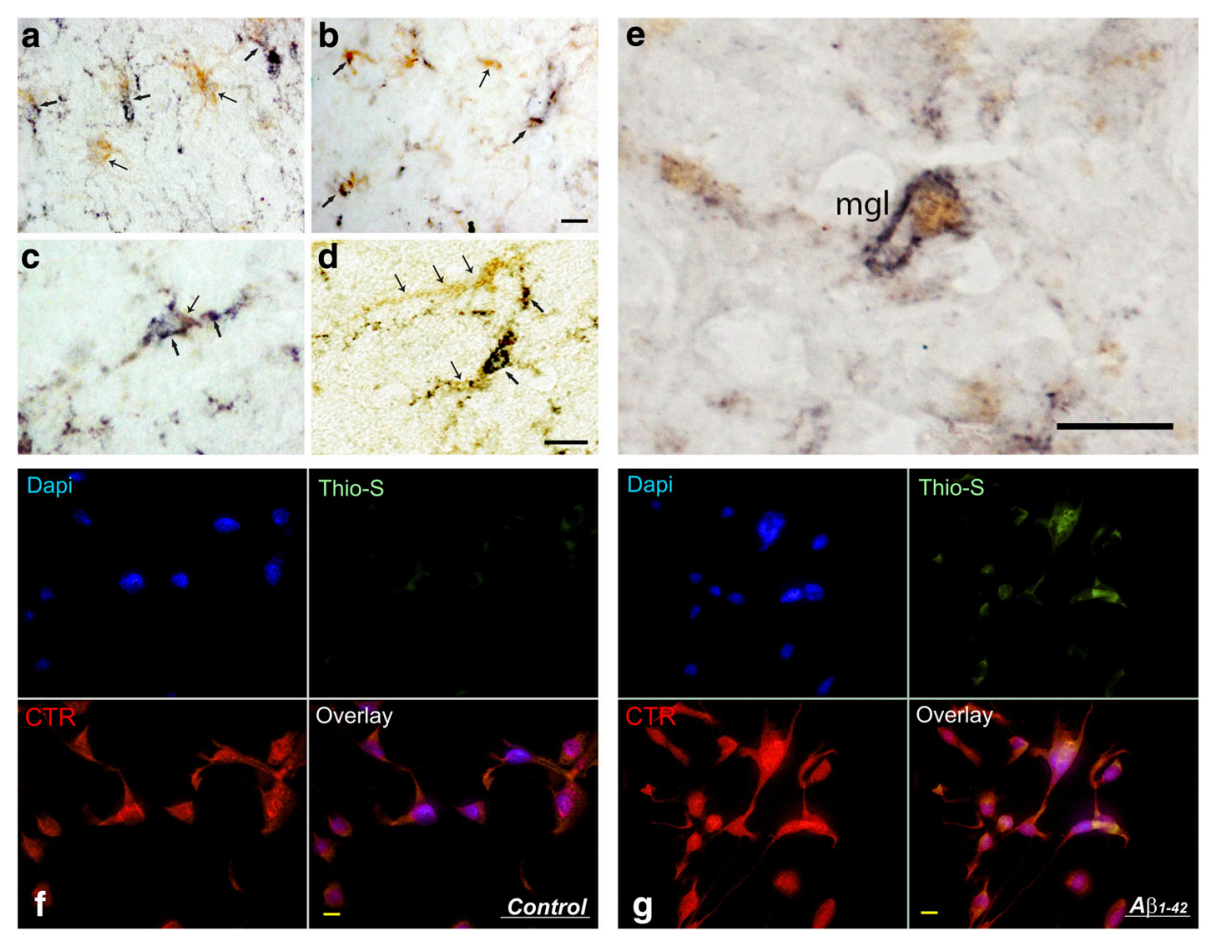

Fig. 2 Amylin receptors on microglia in human Alzheimer's disease brain and BV2 microglial cells. a, b Section from the inferior frontal gyrus of the AD patient (Braak Stage 6) after dual immunostaining both with the antibody to microglial marker lba-1 (yellow) and calcitonin receptor (CTR) (dark blue). Arrows show microglial cells expressing both Iba-1 and CTR; thin arrows point to microglial cells expressing only Iba-1. c, d Single microglial cells are presented at a higher magnification, with thin arrows pointing to Iba-1 location (yellow) and arrows pointing to the CTR location (dark blue). e Coronal section from the inferior frontal gyrus of the AD patient after double immunohistochemical staining with antibody against CTR and receptor activity modifying protein 3 (RAMP3). Notice the microglia-like profile (mgl) expressing both CTR (blue) and RAMP3 (yellow). $\mathbf{f}$ BV2 microglial cells expressed CTR (red). $\mathbf{g}$ These BV2 cells were cultured in the presence of A $\beta_{1-42} 1 \mu \mathrm{M}$ for $24 \mathrm{~h}$. The $A \beta$ was taken up into the cells and formed plaque-like structures stained with thioflavin $\mathrm{S}$ (green). Scale bars $=10 \mu \mathrm{m}$ 

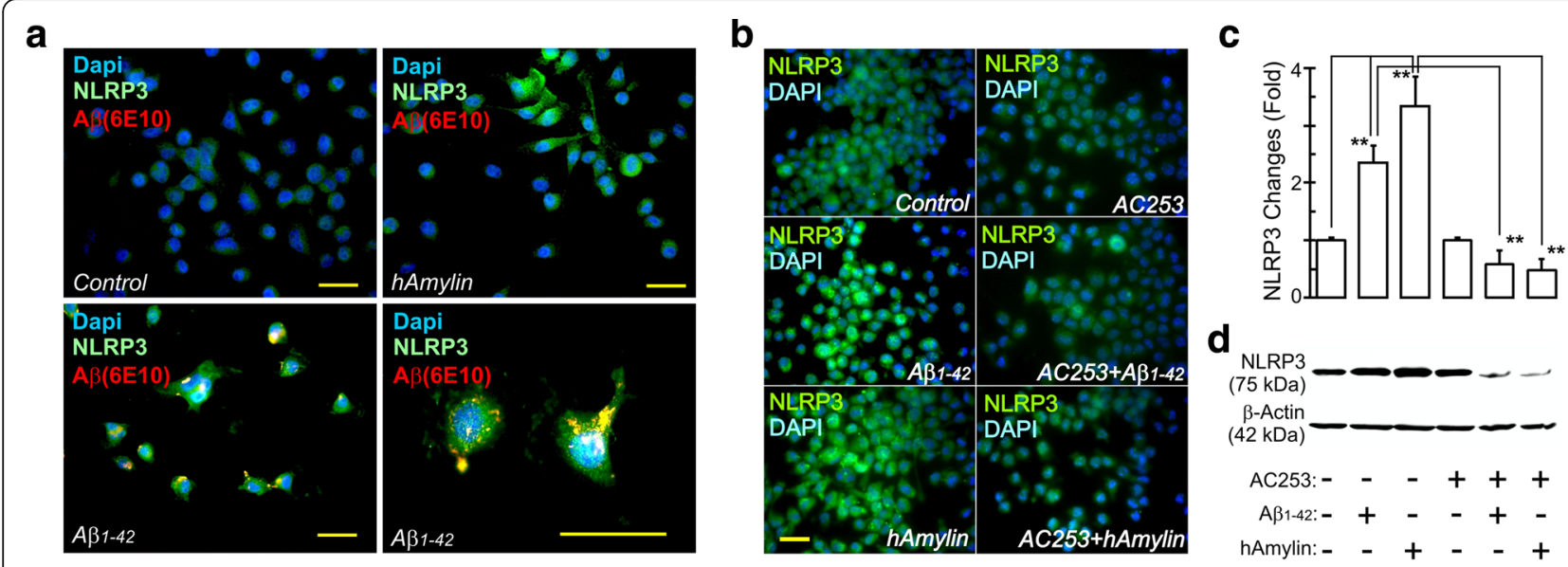

Fig. 3 Amylin receptor mediates activation of inflammasomes in microglia. a Increased activation of the inflammasome, NLRP3 (green), following application of either $A \beta_{1-42}$ or hAmylin human fetal microglial (HFMs) cultures. $A \beta$ is identified with immunostaining with 6 E10 antibody and shows as yellow on account of its co-localization with NLRP3. b BV2 cells (murine microglial cell line) treated either A $\beta_{1-42}$ or hAmylin ( $\left.2 \mu \mathrm{M}\right)$ for $24 \mathrm{~h}$ show a similar increase in NLRP3 staining as in HFMs that is attenuated by $16 \mathrm{~h}$ pre-treatment with AC253 $(10 \mu \mathrm{M})$. c Summary of amylin receptor mediated changes in NLRP3 observed and quantitated from Western blots, an example of which is shown in $\mathbf{d} .{ }^{*} p<0.01$. Scale bar $=20 \mu \mathrm{m}$
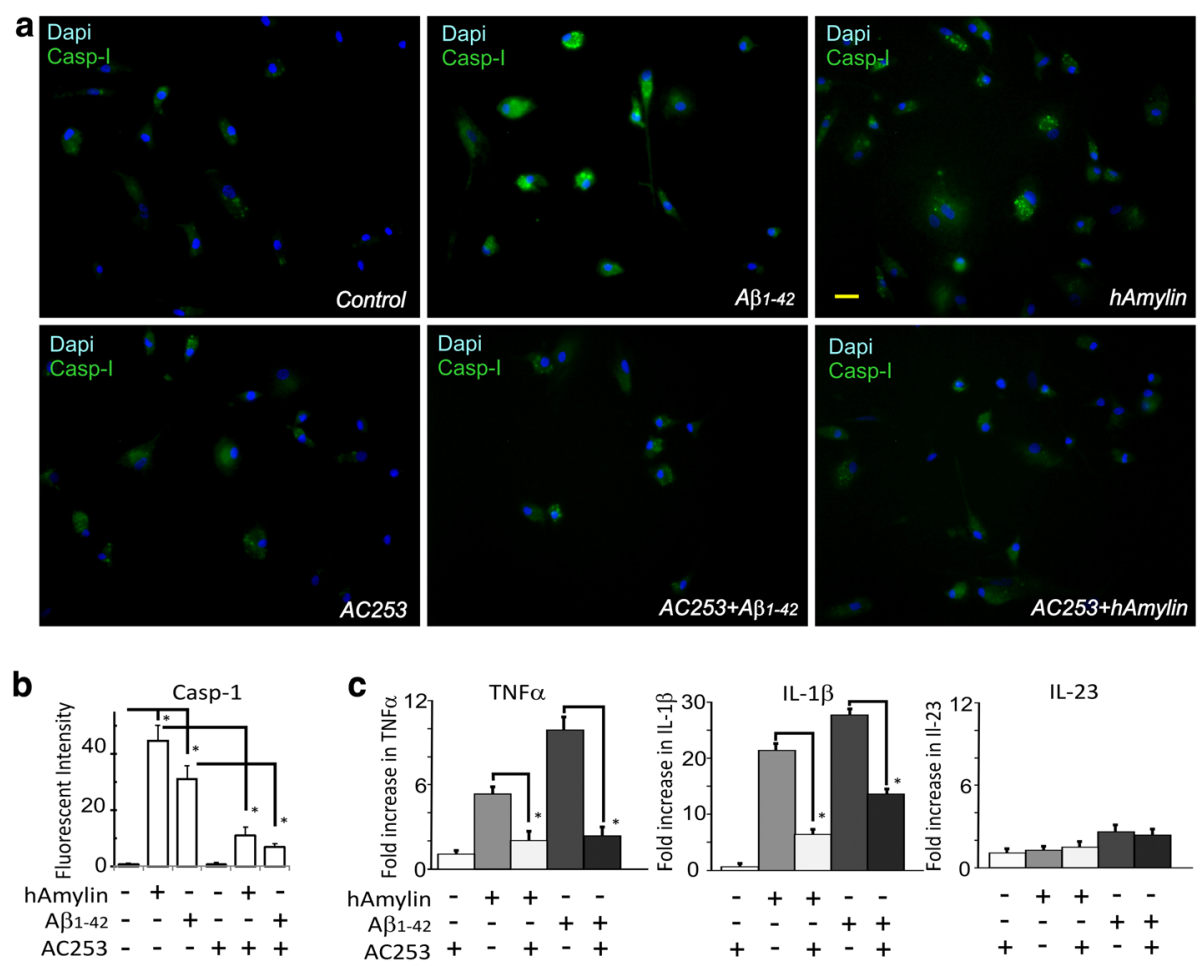

Fig. $4 \mathrm{~A} \beta$ induces upregulation of caspase-1 and pro-inflammatory cytokines in human fetal microglia (HFMs) via amylin receptor. $\mathbf{a}, \mathbf{b} A \beta_{1-42}$ or hAmylin increase caspase-1 expression that is detected by a fluorometric assay (green). Pre-treatment of HFMs with amylin receptor antagonist, AC253 blocks caspase-1 expression. c RT-PCR detection of cytokines (TNFa, IL-10, IL-1 3 , and IL-23) in HFMs treated with either hAmylin, $A \beta_{1-42}$, or AC253. Pre-treatment of HFMs with AC253 markedly attenuates upregulation of TNFa, IL-10, and IL-1 $\beta$, but not IL-23. ${ }^{*} p<0.01$. Scale bar $=20 \mu m$ 
of the linear form of the peptide but is proteolytically stable and highly brain-penetrant when administered intraperitoneally [15]. The pKa $=6.942$ for the cAC253 peptide was calculated from Molecular Operating Environment (MOE) from Chemical Computing Group (Montreal, QC, Canada). The cAC253 also demonstrated a higher level of antagonist activity at AMY receptors with IC50, $0.3 \mu \mathrm{M}$, versus AC253, $0.85 \mu \mathrm{M}$, using in-cell western blot detection [15]. In HEK293 transfected cells, cAC253 demonstrated similar activity as AC253 and blocked hAmylin activation of AMY3 and AMY1 receptors (Additional file 3: Figure S2). We also tested the ability of cAC253 (at different concentrations) to competitively antagonize human amylin-generated cAMP responses across full range of concentrations. We examined the effects of chronic systemic administration of cAC253 on changes in amyloid pathology and inflammatory markers in a transgenic mouse model of $\mathrm{AD}$,
5xFAD. Six and a half-month-old 5xFAD mice that received 5 weeks of cAC253 treatment (ip, three times a week) demonstrated significant reduced amyloid plaque formation, and we observed less number of activated microglial cells compared to 5xFAD mice treated with normal saline (NS) injections (Fig. 5a, b). A $\beta$ deposition was significantly reduced as measured by either the number of $A \beta$ plaques, or total area of $A \beta$-positive profiles in the cAC253-treated 5xFAD animals compared to those receiving NS (Fig. 5b). Wt mice showed no $A \beta$ deposits. Protein expression levels of microglial markers Iba-1 and CD68 (activated microglia), inflammasome NLRP3, and caspase-1 were significantly reduced (approximately 30\%) in cAC253-treated 5xFAD group compared to NS treatment (Fig. 5c, d). Additionally, levels of cytokines IL-1 $\beta$ and TNF $\alpha$ measured by ELISA were also significantly reduced after ip cAC253 treatment (Fig. 5e).

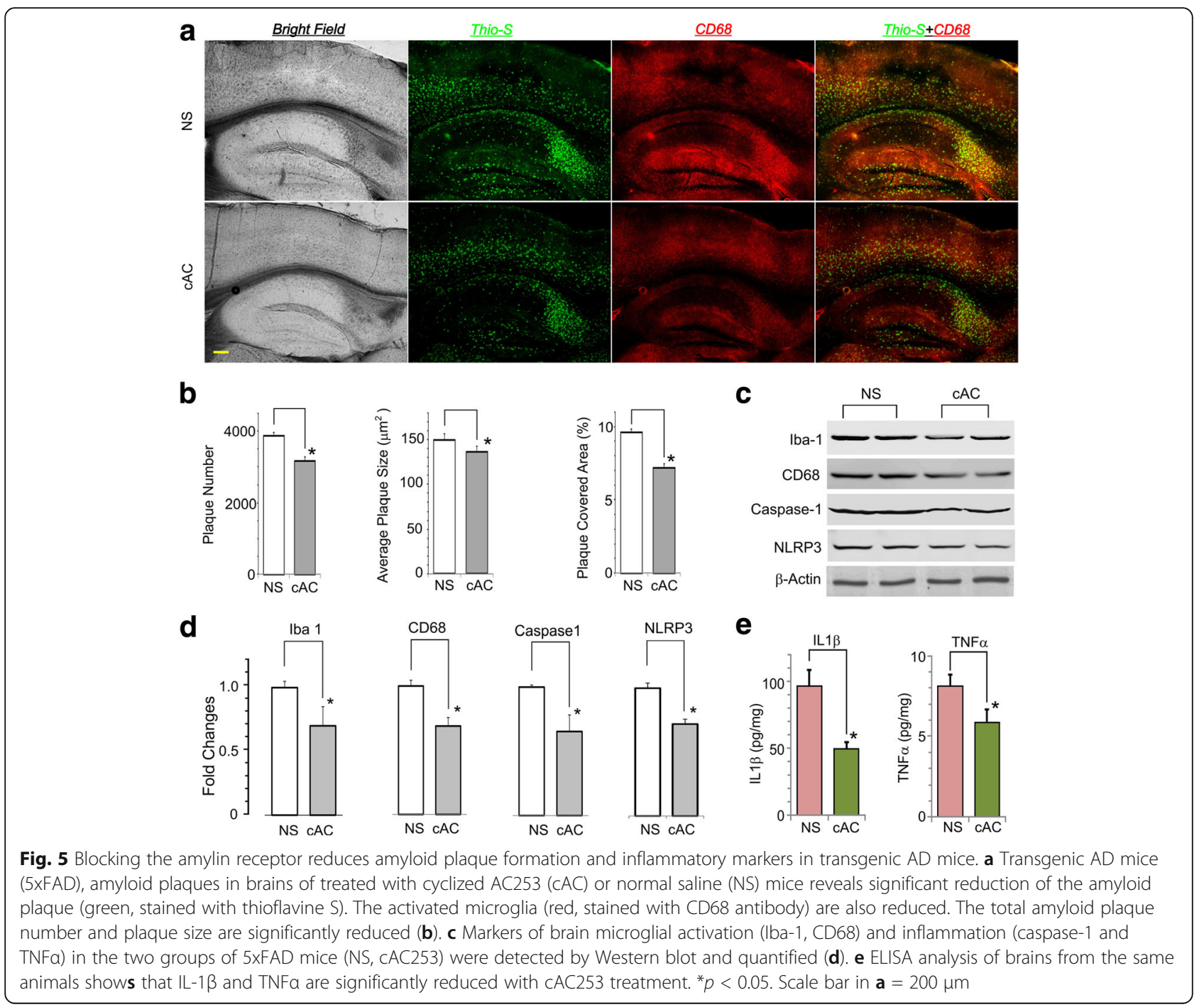




\section{Discussion}

Although recent studies indicate that amylin and amylin receptor are involved in microglia-mediated neuroinflammation in $\mathrm{AD}$ mice [26, 27], this study shows for the first time immunohistochemical presence of amylin receptors on human and murine microglia, which serve as a portal for the expression of the inflammatory effects of $A \beta$ in the brain. Specifically, amylin receptors present on human microglia are functional in that applications of either monomeric hAmylin or soluble oligomeric $\mathrm{A} \beta_{1-42}$ results in an increase in cytosolic $\mathrm{Ca}^{2+}$, a response that is accompanied by activation of the inflammasome, NLRP3, and caspase-1 with the subsequent release of pro-inflammatory cytokines, IL-1 $\beta$ and TNF $\alpha$. Blockade of the amylin receptors with an amylin receptor antagonist, AC253, results in an attenuation of these inflammatory mediators. In a transgenic mouse model of $\mathrm{AD}$, systemic administration of cAC253 leads to an improvement in spatial memory and learning [15], that is, accompanied by diminution of the amyloid burden, and an attenuation of microglial markers within the brain. Collectively, these observations suggest a possible role for the amylin receptor as a target in the therapeutics of AD.
Increasing evidence suggests that $\mathrm{AD}$ pathogenesis involves multiple interacting compartments that include neuronal and synaptic disruption, vascular pathology, and neuroinflammation [1,28]. Of these, neuroinflammation mediated primarily by microglia, which are critical regulators of immune responses, is a key feature of early AD. Microglia are implicated in clearance of $A \beta$ either by phagocytosis or binding to receptors on microglial plasma membrane [28-33]. In vitro and in vivo studies have shown that consequences of $A \beta$ interactions with microglia include lysosomal damage, activation of the NLRP3 inflammasome complex, and the release of cytokine IL-1 $\beta$ in a caspase-1-dependent manner [9]. The uncontrolled release of inflammatory cytokines also elicits upregulation of $A \beta$ via increased APP processing [11], thus perpetuating a vicious cycle of $A \beta$-induced neuronal damage that is a feature of late $\mathrm{AD}$ [28]. Microglial receptors therefore present an attractive target to mitigate both neuroinflammation and neuronal toxicity induced by amyloid as depicted in our working model (Fig. 6). We have previously shown that a pharmacological blockade or genetic depletion of the amylin receptor in the human neuronal cell culture model protects against the $A \beta$-induced toxicity $[14,34]$.

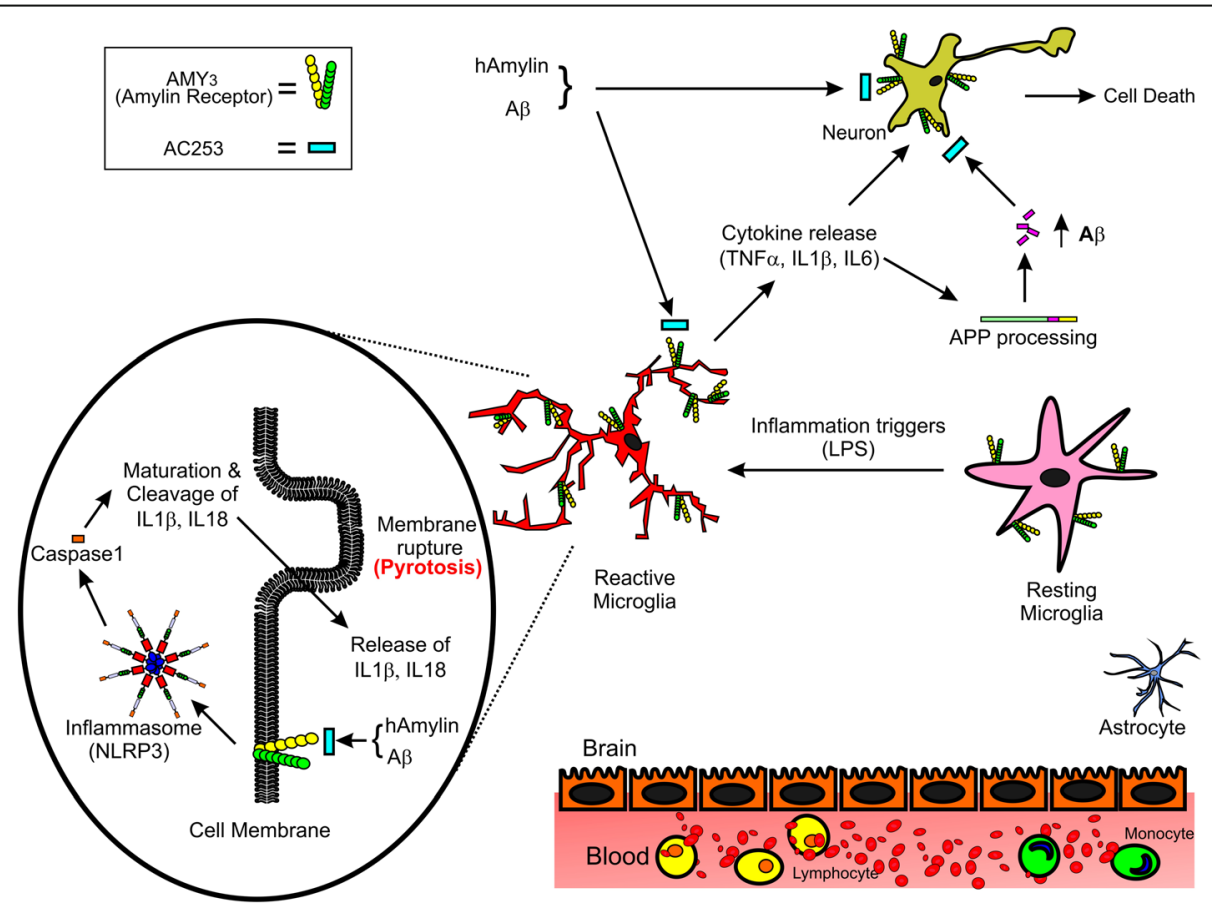

Fig. 6 Proposed model for the role of microglial and neuronal amylin receptors in mediating the amyloid beta (A $\beta$ )-induced neurodegeneration. Amylin receptors, comprised of calcitonin receptor (CTR) and receptor activity modifying protein 3 (RAMP3), are expressed on both neurons and the microglia. The expression of amylin receptors on microglial cells is increased in response to inflammatory triggers, such as lipopolysaccharide $(L P S)$, resulting in activation of these cells. Interaction of $A \beta$ with amylin receptors on the activated microglia leads to increased production and release of cytokines, which act directly on neurons to produce cell death and additionally augment the production of $A \beta$ via processing of the amyloid precursor protein (APP). This A $\beta$, in turn, interacts with neuronal and microglial amylin receptors to produce cell death. The amylin receptor antagonist AC253 acts on both the neuronal and microglial receptors to block the detrimental effects of $A \beta$ and affords protection against the neuronal degeneration 
Here, we show that blockade of microglial amylin receptors with an amylin receptor antagonist, AC253 in vitro, results in attenuation of NLRP3-mediated inflammatory cascade and diminished cytokine release. Furthermore, in a mouse $\mathrm{AD}$ model with systemic administration of cAC253 results in attenuation of key indices of brain inflammation-activated and reactive microglia (Iba-1, CD68), the inflammasome NLRP3, caspase-1, and proinflammatory cytokines, IL-1 $\beta$ and TNF $\alpha$.

In transgenic mouse models of $\mathrm{AD}$, microglial activation is observed to parallel accumulation of amyloid [35, 36] and a similar relationship has also been reported for the human AD using PET ligands [36, 37]. In our study, we administered the amylin receptor antagonist cAC253 intraperitoneally to 5xFAD mice at six and a half months of age, a time point corresponding to the presence of pathological features such as the amyloid accumulation and neuroinflammatory changes [15]. In these in vivo experiments, we chose to use cAC253 on account of its superior stability, pharmacokinetic profile, and brain penetrability when administered systemically compared with linear form of the peptide AC253 [15]. Five weeks posttreatment with cAC253, we observed a significant reduction in both the amyloid burden and indices of neuroinflammation in a manner similar to that observed in vitro. Based on these findings, we conclude that the amylin receptor blockade has the potential to mitigate $A \beta$-induced microglial activation, a key event in AD pathogenesis, and subsequent cytokine-induced neuronal death.

As a neuroendocrine hormone, amylin mediates glycemic regulation, energy balance control, and cognitive/ motivational processes [18]. Human amylin also modulates autoimmunity and innate inflammation through regulatory $\mathrm{T}$ cells $[16,17]$. Amyloid precursor protein (APP) and $A \beta$ interact with variety of G-protein-coupled receptors (GPCRs) including amylin receptors [38]. Amylin receptors (AMYs) are a dimerized calcitonin receptor (CTR) with receptor activity-modifying proteins (RAMPs) and belong to class B GPCRs. We have previously shown that hAmylin and $A \beta$ preferentially activate AMY3 receptor subtype resulting in downstream activation of MAPK and Akt signaling pathways that could be blocked with amylin receptor antagonist, AC253 [23]. At a functional level, application of either AC253 or pramlintide (marketed as a synthetic analog of amylin) attenuate hAmylin- and $A \beta$-induced depression of hippocampal long-term potentiation, a cellular surrogate of memory $[20,39]$. Pramlintide when administered systemically to transgenic AD mice has been shown to reduce amyloid burden in the brain through promoting an efflux of $A \beta$ across the blood brain barrier [40, 41]. Cyclized AC253 may reduce brain amyloid through a similar mechanism. Additionally, we suggest that cAC253, which readily crosses the blood brain barrier, could block both the neuronal and microglial amylin receptors, thereby diminishing the deleterious effects of elevated levels of $A \beta$ in transgenic $A D$ mice. As a consequence, cAC253-treated $\mathrm{AD}$ mice demonstrate not only improved spatial memory as we have reported [24], but also an attenuation of neuroinflammation.

\section{Conclusions}

In this study, we provide evidence that functional amylin receptors are expressed on both human and murine microglia and mediate $A \beta$-induced activation of the inflammatory cascade of NLRP3 and caspase-1 with subsequent release of cytokines. Amylin receptor antagonism can attenuate these pro-inflammatory events in vitro. Chronic administration of such an antagonist results in improvement in amyloid burden and inflammatory markers in an AD mouse model. This supports the idea inflammatory changes in the brain that contribute to cognitive dysfunction in $\mathrm{AD}$ may, in part, be mediated via the amylin receptor. Furthermore, amylin receptor antagonists are capable of attenuating $A \beta$-evoked inflammation. Thus, amylin microglial receptors could provide novel treatment for $\mathrm{AD}$ specifically by targeting neuroinflammation, an early event in this disease.

\section{Additional files}

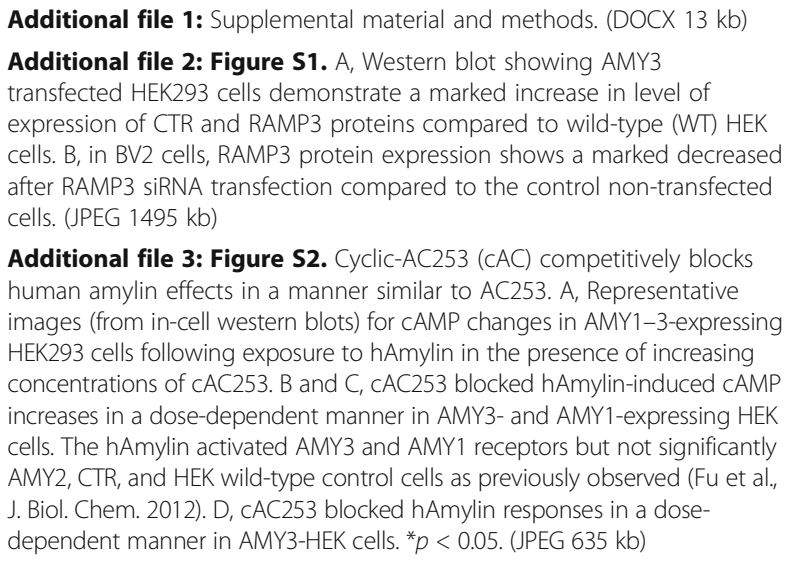

Additional file 3: Figure S2. Cyclic-AC253 (CAC) competitively blocks human amylin effects in a manner similar to AC253. A, Representative images (from in-cell western blots) for CAMP changes in AMY1-3-expressing HEK293 cells following exposure to hAmylin in the presence of increasing concentrations of CAC253. B and C, CAC253 blocked hAmylin-induced CAMP increases in a dose-dependent manner in AMY3- and AMY1-expressing HEK cells. The hAmylin activated AMY3 and AMY1 receptors but not significantly AMY2, CTR, and HEK wild-type control cells as previously observed (Fu et al., J. Biol. Chem. 2012). D, CAC253 blocked hAmylin responses in a dosedependent manner in AMY3-HEK cells. ${ }^{*} p<0.05$. (JPEG $635 \mathrm{~kb}$ )

\begin{abstract}
Abbreviations
ABC: Avidin-biotin complex; AD: Alzheimer's disease; AMYs: Amylin receptors; ANOVA: One-way analysis of variance; Aß: Beta-amyloid; CAC253: Cyclized form of the amylin receptor antagonist AC253; CTR: Calcitonin receptor; ELISA: Enzyme-linked immunosorbent assay; hAmylin: Human amylin; HFM: Human fetal microglia; LTP: Long-term potentiation; IFG: Human inferior temporal gyrus; ip: Intraperitoneal injection; NS: Normal saline; PAF: Paraformaldehyde; PBS: Phosphate-buffered saline; RAMPs: Receptor activity-modifying proteins; RP-HPLC: Reversed phase high-performance liquid chromatography; TBS: Tris-buffered saline; Tg: Transgenic
\end{abstract}

Acknowledgements

We thank Dr. Khem Jhamandas for the useful comments on the manuscript. 


\section{Funding}

This research was supported by the grants from the Canadian Institutes of Health Research, University Hospital Foundation, and the Natural Sciences and Engineering Research Council of Canada (NSERC). Rania Soudy is a recipient of Alberta Innovates Heath Sciences (AlHS) clinician postdoctoral fellowship.

\section{Availability of data and materials}

All data generated or analyzed during this study are included in this published article.

\section{Authors' contributions}

WF, W, AP, RS, DM, and VG designed and performed the research and analyzed the data; DW and KK provided the reagents/analytic tools; WF and JJ designed the experiments and wrote the manuscript. All authors read and approved the final manuscript.

\section{Ethics approval}

All experiments were conducted in compliance with the guidelines set by the Canadian Council for Animal Care and with the approval of the Human Research Ethics Board and Animal Care Use Committee (Biomedical Sciences) at the University of Alberta.

\section{Consent for publication}

Not applicable

\section{Competing interests}

The authors declare that they have no competing interests.

\section{Publisher's Note}

Springer Nature remains neutral with regard to jurisdictional claims in published maps and institutional affiliations.

\section{Author details}

'Department of Medicine (Neurology), Neuroscience and Mental Health Institute, University of Alberta, 530 Heritage Medical Research Centre, Edmonton, AB T6G 2S2, Canada. 'Faculty of Pharmacy, Cairo University, Cairo, Egypt. ${ }^{3}$ Department of Biochemistry, University of Alberta, Edmonton, $A B$, Canada. ${ }^{4}$ Centre for Prions and Protein Folding Diseases, University of Alberta, Edmonton, AB, Canada. ${ }^{5}$ Chapman University School of Pharmacy, Irvine, CA, USA. ${ }^{6}$ Russian Cardiology Research Center, Moscow, Russia.

Received: 15 May 2017 Accepted: 27 September 2017

Published online: 06 October 2017

\section{References}

1. Vinters HV. Emerging concepts in Alzheimer's disease. Annu Rev Pathol. 2015:10:291-319.

2. Aguzzi A, Barres BA, Bennett ML. Microglia: scapegoat, saboteur, or something else? Science. 2013;339:156-61.

3. Czirr E, Wyss-Coray T. The immunology of neurodegeneration. J Clin Invest. 2012;122:1156-63.

4. Griffin WS. Neuroinflammatory cytokine signaling and Alzheimer's disease. N Engl J Med. 2013;368:770-1.

5. Yates SL, Burgess LH, Kocsis-Angle J, Antal JM, Dority MD, Embury PB, Piotrkowski AM, Brunden KR. Amyloid beta and amylin fibrils induce increases in proinflammatory cytokine and chemokine production by THP-1 cells and murine microglia. J Neurochem. 2000;74:1017-25.

6. Mariathasan S, Monack DM. Inflammasome adaptors and sensors: intracellular regulators of infection and inflammation. Nat Rev Immunol. 2007;7:31-40

7. Halle A, Hornung V, Petzold GC, Stewart CR, Monks BG, Reinheckel T, et al. The NALP3 inflammasome is involved in the innate immune response to amyloid-beta. Nat Immunol. 2008:9:857-65.

8. Singhal G, Jaehne EJ, Corrigan F, Toben C, Baune BT. Inflammasomes in neuroinflammation and changes in brain function: a focused review. Front Neurosci. 2014;8:315

9. Walsh JG, Muruve DA, Power C. Inflammasomes in the CNS. Nat Rev Neurosci. 2014;15:84-97.

10. Bergsbaken T, Fink SL, Cookson BT. Pyroptosis: host cell death and inflammation. Nat Rev Microbiol. 2009;7:99-109.
11. Blasko I, Marx F, Steiner E, Hartmann T, Grubeck-Loebenstein B. TNFalpha plus IFNgamma induce the production of Alzheimer beta-amyloid peptides and decrease the secretion of APPs. FASEB J. 1999;13:63-8.

12. Solé-Domènech $\mathrm{S}$, Cruz DL, Capetillo-Zarate E, Maxfield FR. The endocytic pathway in microglia during health, aging and Alzheimer's disease. Ageing Res Rev. 2016:32:89-103.

13. Gold M, El Khoury J. $\beta$-amyloid, microglia, and the inflammasome in Alzheimer's disease. Semin Immunopathol. 2015;37:607-11.

14. Jhamandas JH, Li Z, Westaway D, Yang J, Jassar S, MacTavish D. Actions of $\beta$-amyloid protein on human neurons are expressed through the amylin receptor. Am J Pathol. 2011;178:140-9.

15. Soudy R, Patel A, Fu W, Kaur K, MacTavish D, Westaway D, Davey R, Zajac J, Jhamandas J. Cyclic AC253, a novel amylin receptor antagonist, improves cognitive deficits in a mouse model of Alzheimer's. Alzheimer's and Dementia: Translational Research and Clinical Interventions. 2017:3:44-56.

16. Westwell-Roper C, Dunne A, Kim ML, Verchere CB, Masters SL. Activating the NLRP3 inflammasome using the amyloidogenic peptide IAPP. Methods Mol Biol. 2013;1040:9-18

17. Baker RL, Delong T, Barbour G, Bradley B, Nakayama M, Haskins K. Cutting edge: CD4 T cells reactive to an islet amyloid polypeptide peptide accumulate in the pancreas and contribute to disease pathogenesis in nonobese diabetic mice. J Immunol. 2013;191:3990-4.

18. Mietlicki-Baase EG. Amylin-mediated control of glycemia, energy balance, and cognition. Physiol Behav. 2016;162:130-40.

19. Jhamandas JH, MacTavish D. Antagonist of the amylin receptor blocks betaamyloid toxicity in rat cholinergic basal forebrain neurons. J Neurosci. 2004; 24:5579-84.

20. Kimura R, MacTavish D, Yang J, Westaway D, Jhamandas JH. Beta amyloidinduced depression of hippocampal long-term potentiation is mediated through the amylin receptor. J Neurosci. 2012;32:17401-6.

21. Durafourt BA, Moore CS, Blain M, Antel JP. Isolating, culturing, and polarizing primary human adult and fetal microglia. Methods Mol Biol. 2013; 1041:199-211.

22. Walsh JG, Reinke SN, Mamik MK, McKenzie BA, Maingat F, Branton WG, Broadhurst DI, Power C. Rapid inflammasome activation in microglia contributes to brain disease in HIV/AIDS. Retrovirology. 2014:11:35.

23. Fu W, Ruangkittisakul A, MacTavish D, Shi JY, Ballanyi K, Jhamandas JH. Amyloid $\beta(A \beta)$ peptide directly activates amylin-3 receptor subtype by triggering multiple intracellular signaling pathways. J Biol Chem. 2012;287: 18820-30.

24. Ruangkittisakul A, Schwarzacher SW, Secchia L, Poon BY, Ma Y, Funk GD, Ballanyi K. High sensitivity to neuromodulator-activated signaling pathways at physiological $[\mathrm{K}+]$ of confocally-imaged respiratory center neurons in online-calibrated newborn rat brainstem slices. J Neurosci. 2006;26:11870-

25. Dahlgren KN, Manelli AM, Stine WB Jr, Baker LK, Krafft GA, LaDu MJ. Oligomeric and fibrillar species of amyloid-beta peptides differentially affect neuronal viability. J Biol Chem. 2002;277:32046-53.

26. Wang E, Zhu H, Wang X, Gower AC, Wallack M, Blusztajn JK, et al. Amylin treatment reduces neuroinflammation and ameliorates abnormal patterns of gene expression in the cerebral cortex of an Alzheimer's disease mouse model. J Alzheimers Dis. 2017;56:47-61.

27. Zhu $\mathrm{H}$, Xue $\mathrm{X}$, Wang $\mathrm{E}$, Wallack $\mathrm{M}, \mathrm{Na} \mathrm{H}$, Hooker JM, et al. Amylin receptor ligands reduce the pathological cascade of Alzheimer's disease. Neuropharmacology. 2017;119:170-81. https://doi.org/10.1016/j.neuropharm. 2017.03.030

28. ElAli A, Rivest S. Microglia in Alzheimer's disease: a multifaceted relationship. Brain Behav Immun. 2016:55:138-50.

29. Oakley H, Cole SL, Logan S, Maus E, Shao P, Craft J, Guillozet-Bongaarts A Ohno M, Disterhoft J, Van Eldik L, Berry R, Vassar R. Intraneuronal betaamyloid aggregates, neurodegeneration, and neuron loss in transgenic mice with five familial Alzheimer's disease mutations: potential factors in amyloid plaque formation. J Neurosci. 2006;4(26):10129-40.

30. Heneka MT, Carson MJ, El Khoury J, Landreth GE, Brosseron F, Feinstein DL, et al. Neuroinflammation in Alzheimer's disease. Lancet Neurol. 2015;14:388-405.

31. Heneka MT, Golenbock DT, Latz E. Innate immunity in Alzheimer's disease. Nat Immunol. 2015;16:229-36.

32. Wes PD, Sayed FA, Bard F, Gan L. Targeting microglia for the treatment of Alzheimer's disease. Glia. 2016;64:1710-32.

33. Heppner FL, Ransohoff RM, Becher B. Immune attack: the role of inflammation in Alzheimer disease. Nat Rev Neurosci. 2015;16:358-72. 
34. Jhamandas $\mathrm{JH}$, MacTavish D. $\beta$-Amyloid protein $(A \beta)$ and human amylin regulation of apoptotic genes occurs through the amylin receptor. Apoptosis. 2012;17:37-47.

35. Brendel M, Kleinberger G, Probst F, Jaworska A, Overhoff F, Blume $T$, et al. Increase of TREM2 during aging of an Alzheimer's disease mouse model is paralleled by microglial activation and amyloidosis. Front Aging Neurosci. 2017;9:8. http://doi.org/10.3389/fnagi.2017.00008

36. Hommet C, Mondon K, Camus V, Ribeiro MJ, Beaufils E, Arlicot N, Corcia P, Paccalin M, Minier F, Gosselin T, Page G, Guilloteau D, Chalon S.

Neuroinflammation and $\beta$ amyloid deposition in Alzheimer's disease: in vivo quantification with molecular imaging. Dement Geriatr Cogn Disord. 2014; 37:1-18.

37. Hamelin L, Lagarde J, Dorothée G, Leroy C, Labit M, Comley RA, et al. Early and protective microglial activation in Alzheimer's disease: a prospective study using 18 F-DPA-714 PET imaging. Brain. 2016;139:1252-64. https://doi. org/10.1093/brain/aww017.

38. Deyts C, Thinakaran G, Parent AT. APP receptor? To be or not to be. Trends Pharmacol Sci. 2016;37:390-411.

39. Kimura R, MacTavish D, Yang J, Westaway D, Jhamandas JH. Pramlintide antagonizes beta amyloid (A $\beta$ )- and human amylin-induced depression of hippocampal long-term potentiation. Mol Neurobiol. 2016;54:748-54. https://doi.org/10.1007/s12035-016-9684-x.

40. Adler BL, Yarchoan M, Hwang HM, Louneva N, Blair JA, Palm R, et al. Neuroprotective effects of the amylin analogue pramlintide on Alzheimer's disease pathogenesis and cognition. Neurobiol Aging. 2014;35:793-801.

41. Zhu H, Wang X, Wallack M, Li H, Carreras I, Dedeoglu A, et al. Intraperitoneal injection of the pancreatic peptide amylin potently reduces behavioral impairment and brain amyloid pathology in murine models of Alzheimer's disease. Mol Psychiatry. 2015;20:252-62

\section{Submit your next manuscript to BioMed Central and we will help you at every step:}

- We accept pre-submission inquiries

- Our selector tool helps you to find the most relevant journal

- We provide round the clock customer support

- Convenient online submission

- Thorough peer review

- Inclusion in PubMed and all major indexing services

- Maximum visibility for your research

Submit your manuscript at www.biomedcentral.com/submit 